\title{
Resistência biológica da madeira tratada de duas espécies de Eucalyptus em ensaio de campo
}

\author{
Magnos Alan Vivian', Elio José Santini², Karina Soares Modes ${ }^{3}$, Douglas Edson Carvalho4 ${ }^{4}$ Weslley Wilker Corrêa Morais ${ }^{5}$ \\ ${ }^{1}$ Universidade Federal de Santa Catarina, Campus Curitibanos, Rod. Ulysses Gaboardi, Km 3, CEP 89.520-000, Curitibanos, SC, Brasil \\ ${ }^{2}$ Universidade Federal de Santa Maria, Departamento de Ciências Florestais, Av. Roraima, 1000, CEP 97.105-900, Santa Maria, RS, Brasil \\ ${ }^{3}$ Universidade Federal de Rondônia, Campus Rolim de Moura, CEP 78.987-000, Rolim de Moura, RO, Brasil \\ ${ }^{4}$ Universidade Federal do Paraná, Rua XV de Novembro, 1299, CEP 80.060-000, Curitiba, PR, Brasil \\ ${ }^{5}$ Universidade Estadual de Roraima, Rodovia 210, Km 70, CEP 69.375-000, São João da Baliza, RR, Brasil
}

"Autor correspondente:

magnosalan@usp.br

Termos para indexação:

Tratamento preservativo

Campo de apodrecimento

Perda de massa

Index terms:

Preservative treatment

Field decay

Weight loss

Histórico do artigo:

Recebido em 01/06/2013

Aprovado em 15/12/2014

Publicado em 31/12/2014

doi: 10.4336/2014.pfb.34.80.545
Resumo - A madeira, devido sua origem orgânica, dependendo das condições ambientais que seja exposta, pode ser deteriorada por agentes biológicos. Em vista disto, é extremamente importante que passe por algum tratamento preservativo, com o intuito de aumentar sua vida útil. A presente pesquisa teve por objetivo avaliar a resistência biológica de madeira tratada de Eucalyptus grandis e Eucalyptus cloeziana sob a ação de organismos biodeterioradores em ensaios de campo. Para tanto, foram utilizadas árvores de $E$. grandis e $E$. cloeziana, com 16 anos de idade, que foram desdobradas em tábuas e submetidas à secagem ao ar livre para, posteriormente, efetuar-se o tratamento preservativo em autoclave com arseniato de cobre cromatado (CCA). Em seguida, foram confeccionados corpos de prova para realização do ensaio de campo. Observou-se que o tratamento preservativo foi eficiente na redução da degradação biológica das madeiras das duas espécies. Comparando-se os resultados obtidos para as duas espécies, observou-se que $E$. cloeziana possui maior aptidão para ser utilizado em condições adversas ou em contato com o solo.

\section{Biological resistance of treated wood of two species of Eucalyptus in field trial}

\begin{abstract}
Wood can be damaged by biological agents due to its organic origin and environmental conditions. To protect the wood and increase its useful life it is necessary to submit it to preservative treatment. So, the present study aimed to evaluate the biological resistance of the treated wood of Eucalyptus grandis and Eucalyptus cloeziana under the action of biological organisms in field trials. We used trees of $E$. grandis and E. cloeziana, with 16 years old, which were split into planks and submitted to drying outdoors to later make up the preservative treatment in an autoclave with chromated copper arsenate (CCA). The samples were prepared to conduct the test field. It was observed that the preservative treatment was effective in reducing the biological degradation of wood from both species. Comparing the results obtained for the two species, it was observed that E. cloeziana presents greater ability to be used in adverse conditions or in contact with the ground.
\end{abstract}




\section{Introdução}

A madeira, por ser material de origem orgânica, dependendo das condições ambientais, pode ser deteriorada tanto por agentes biológicos, como microorganismos (bactérias e fungos), insetos (coleópteros e térmitas) e brocas marinhas (moluscos e crustáceos), bem como por reações químicas, o que traz prejuízo aos seus usuários, no que se refere ao custo da mão-de-obra para substituição do material e ao risco à segurança da obra.

Segundo Calil Júnior \& Dias (1997), a ideia equivocada de que a madeira tem vida útil curta, tem levado a negligenciá-la como material de construção. Embora seja susceptível ao ataque de organismos deterioradores sob condições específicas, quando preparada com tecnologia e tratamento preservativo, torna-se um material muito durável, tendo em vista que se pode obter proteção efetiva por períodos de até 50 anos ou mais.

Quando a situação de uso da madeira à submete a condições adversas ou ao contato com o solo, tornase necessário o uso de espécies de alta durabilidade natural ou de baixa durabilidade, mas com facilidade de impregnação quando submetidas a tratamento preservativo, por meio da adição de produtos químicos; tornando-a mais resistente principalmente ao ataque biológico, que são os principais deterioradores da madeira em curto prazo, aumentando consideravelmente sua vida útil (Barillari \& Freitas, 2002).

Considerando que as espécies de alta durabilidade natural são provenientes de florestas tropicais, a utilização de espécies de florestas plantadas, e que possam ser submetidas ao tratamento preservativo, torna-se uma alternativa promissora.

Nesse contexto, entram as espécies do gênero Pinus e Eucalyptus que, devido à boa adaptação às condições edafoclimáticas do Brasil, possuem altas taxas de crescimento e potencial para diversos usos, incluindo a produção madeireira (Golfari, 1978). Contudo, a utilização da madeira de reflorestamentos como produtos que requeiram tratamento preservativo está concentrada principalmente no gênero Eucalyptus.

A importância do gênero Eucalyptus tem crescido consideravelmente no Brasil nos últimos anos, entretanto, são poucas as informações sobre as melhores formas de tratamento preservativo desta madeira, necessárias, principalmente, devido à baixa permeabilidade da madeira desta espécie, o que resulta em uma deficiente penetração do produto preservativo além da região periférica da madeira de alburno.

Entre os métodos de tratamento da madeira, existem os sem pressão ou caseiros e os com pressão, também chamados de industriais. Segundo Mendes \& Alves (1988), este último se destaca pela qualidade do tratamento, no que diz respeito à eficiência, ao controle da retenção e penetração do preservativo na madeira, à economia de tempo e a garantia de maior proteção, aumentando consideravelmente a vida útil das peças em serviço.

Segundo Barillari (2002), a eficiência dos produtos preservativos aplicados à madeira pode ser avaliada por ensaios de campo em locais conhecidos como campos de apodrecimento, onde a madeira é exposta ao solo, às intempéries do ambiente, aos fungos e insetos xilófagos.

Nesse contexto, desenvolveu-se a presente pesquisa com o objetivo de avaliar a resistência biológica da madeira tratada de Eucalyptus grandis W. Hill ex Maiden e Eucalyptus cloeziana F. Muell, submetidas à ação de organismos biodeterioradores em ensaios de campo, comparando-se os parâmetros obtidos para as madeiras com e sem tratamento.

\section{Material e métodos}

\section{Obtenção do material}

O material utilizado no estudo foi coletado em um povoamento pertencente à uma empresa localizada próxima a grande Porto Alegre, RS. As árvores de Eucalyptus grandis e Eucalyptus cloeziana, ambas com 16 anos de idade, foram abatidas, transformadas em toras de 2,0 $\mathrm{m}$ de comprimento e transportadas para a serraria da empresa. Na serraria, as toras foram desdobradas tangencialmente em tábuas com as dimensões de $2,2 \times$ $9,0 \times 200,0 \mathrm{~cm}$, de acordo com os padrões utilizados pela empresa para a produção de decks de madeira.

Depois de serrada, a madeira foi submetida a secagem ao ar livre até atingir umidade inferior ao ponto de saturação das fibras (PSF), de 12\% a 15\%, para viabilizar a realização do tratamento preservativo em autoclave. Uma parte das tábuas não foi submetida ao tratamento preservativo, sendo utilizada como comparativo (controle).

\section{Condução do tratamento preservativo}

$\mathrm{O}$ tratamento preservativo da madeira foi executado numa autoclave, com dimensões $2,10 \mathrm{~m}$ de diâmetro e $24,0 \mathrm{~m}$ de comprimento. As tábuas, após passarem pelo 
período de secagem ao ar, foram empilhadas sobre as vagonetas, as quais foram introduzidas no cilindro de tratamento, seguindo as fases do processo Bethell de célula cheia, com uma pressão máxima de $12 \mathrm{kgf.cm}{ }^{-2}$ (Sales Campos et al., 2003).

Como produto preservativo foi utilizado o arseniato de cobre cromatado tipo $\mathrm{C}$ (CCA-C), que é um preservativo hidrossolúvel, fungicida e inseticida com boa mobilidade na madeira. Todos os procedimentos e operações para execução do tratamento das tábuas seguiram a rotina utilizada pela empresa nos tratamentos industriais de madeira serrada. O CCA-C utilizado continha $60 \%$ de ingredientes ativos, ou seja, ácido crômico: $28,5 \%$; óxido cúprico: $11,1 \%$; pentóxido de arsênio: $20,4 \%$ e $40,0 \%$ de inertes.

Para cada uma das espécies de eucalipto utilizadas, realizou-se o tratamento de uma carga de madeira, com as dimensões citadas anteriormente $(2,2 \times 9,0 \times 200,0$ $\mathrm{cm})$. Após o tratamento, foram coletadas 20 tábuas de cada espécie que foram utilizadas na condução do experimento.

Após a retirada da autoclave, as peças tratadas passaram por um período de repouso de 30 a 40 dias, para que ocorresse a evaporação do solvente (a água) e, com isso, a fixação dos ingredientes ativos na madeira. Posteriormente foram confeccionados os corpos de prova utilizados nos ensaios de campo de apodrecimento, com dimensões de 2,0 cm x 2,0 cm x 30,0 cm.

\section{Instalação do ensaio de campo de apodrecimento}

A instalação dos corpos de prova em campo de apodrecimento foi realizada em duas situações distintas, uma em campo aberto e outra em floresta. Para isso, os corpos de prova das duas espécies estudadas foram divididos de forma sistemática, e instalados nessas duas áreas, conforme o esquema ilustrado na Figura 1.
Foram levantadas as condições climáticas da região, como as oscilações de temperatura, umidade relativa do ar e os níveis pluviométricos do local durante o período de execução dos testes, utilizando-se as informações da Estação Experimental de Meteorologia da UFSM.

A cada 60 dias, cinco amostras por tratamento foram retiradas do campo experimental de forma sistemática, as quais passaram por uma limpeza para remoção da terra e posteriormente foram levadas para condicionamento em câmara climatizada. Durante todo o período de condução do experimento, foram realizadas seis avaliações: aos 0 , 60, 120, 180, 240 e 300 dias de exposição em campo. Para avaliar o material submetido ao ensaio de campo, foram realizadas as determinações de perda de massa e índice de comportamento.

\section{Perda de massa e índice de comportamento}

Para avaliação da perda de massa, as amostras foram mantidas em câmara climática a $20{ }^{\circ} \mathrm{C}$ de temperatura e $65 \%$ de umidade relativa até estabilização da massa das mesmas, antes de serem levadas para o campo e após serem retiradas do mesmo, para eliminar o efeito da umidade da madeira. Assim, com base nos valores de massa inicial e final calculou-se a perda de massa (PM) de cada uma das amostras, conforme a Equação 1.

$\mathrm{PM}=\frac{\mathrm{Mi}-\mathrm{Mf}}{\mathrm{Mi}} \times 100$

Em que:

$\mathrm{PM}=$ perda de massa, $\%$

$\mathrm{Mi}=$ massa inicial, $\mathrm{g}$

$\mathrm{Mf}=$ massa final, $\mathrm{g}$

O índice de comportamento, segundo Lepage (1970), é um critério subjetivo de avaliação do estado de deterioração das amostras de madeira, levando-se em consideração notas, de acordo com a Tabela 1.

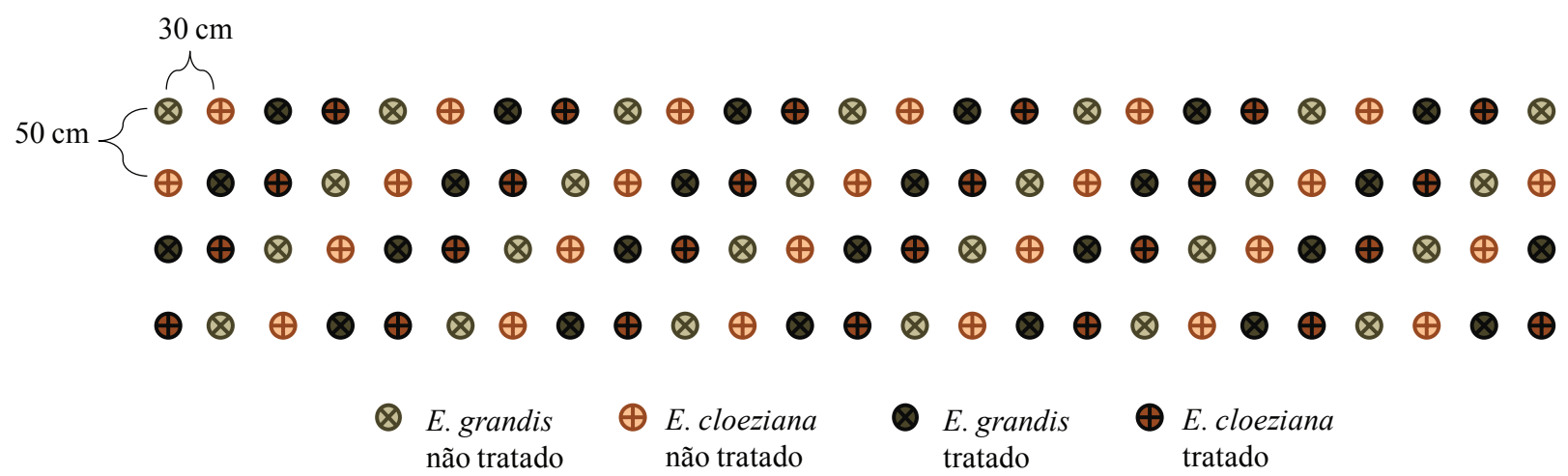

Figura 1. Croqui ilustrativo da instalação do campo de apodrecimento. 
Tabela 1. Classificação da deterioração da madeira.

\begin{tabular}{lcc}
\hline \multicolumn{1}{c}{ Estado de sanidade } & Nota & Índice de deterioração \\
\hline Sadio, nenhum ataque & 0 & 100 \\
Ataque leve ou superficial de fungos e térmitas & 1 & 90 \\
Ataque evidente mas moderado de fungos e térmitas & 2 & 70 \\
Apodrecimento intenso ou ataque intenso de térmitas & 3 & 40 \\
Quebra, perda quase total de resistência & 4 & 0 \\
\hline
\end{tabular}

(Fonte: Lepage, 1970)

\section{Análise estatística}

Os dados foram processados e analisados a partir do programa de análise estatística "Statistical Package for Social Science" (SPSS, v. 15), por meio do qual foram ajustadas equações lineares que explicassem o comportamento do material ao longo do tempo.

\section{Resultados e discussão}

\section{Condições climáticas do período}

Na Figura 2 são apresentadas as variáveis observadas no período de execução do estudo de campo, com as médias mensais de temperatura, umidade relativa e precipitação pluviométrica.

É possível perceber que o nível pluviométrico do período de realização do estudo foi muito superior nos meses de janeiro, julho e setembro, já nos meses de março, outubro e novembro, as precipitações foram extremamente baixas. Nos demais meses do ano, os níveis pluviométricos foram próximos à média da região. Para a temperatura e umidade relativa do ar, os valores foram próximos às médias relatadas, com base nos anos anteriores, sem grandes variações.
Oliveira et al. (1986) afirmaram que as condições de temperatura, umidade e precipitação são importantes na determinação dos micro-organismos aptos a colonizar a madeira e decompô-la e têm marcante influência na velocidade da decomposição. Temperaturas entre $5{ }^{\circ} \mathrm{C}$ e $65^{\circ} \mathrm{C}$ permitem o desenvolvimento desses microorganismos, entretanto são poucos os que crescem com temperaturas acima de $35^{\circ} \mathrm{C}$ ou $40{ }^{\circ} \mathrm{C}$. No entanto, como diferentes espécies de organismos possuem diferentes tolerâncias e pontos ótimos de temperaturas, este fator pode influenciar intensamente a composição de espécies das populações que colonizaram o material nos diferentes estágios seriais da degradação.

Diversas pesquisas levam em consideração a influência destes fatores ambientais, tais como temperatura, umidade e níveis pluviométricos na ocorrência de organismos biodeterioradores no solo, como fungos e bactérias. Entre estas, Monteiro (1994) e Dionísio (1994), estudando solo permanentemente coberto com vegetação, identificaram uma acentuada redução na quantidade de fungos em períodos de maior precipitação pluviométrica. Os autores justificaram que possivelmente ocorreu influência do processo

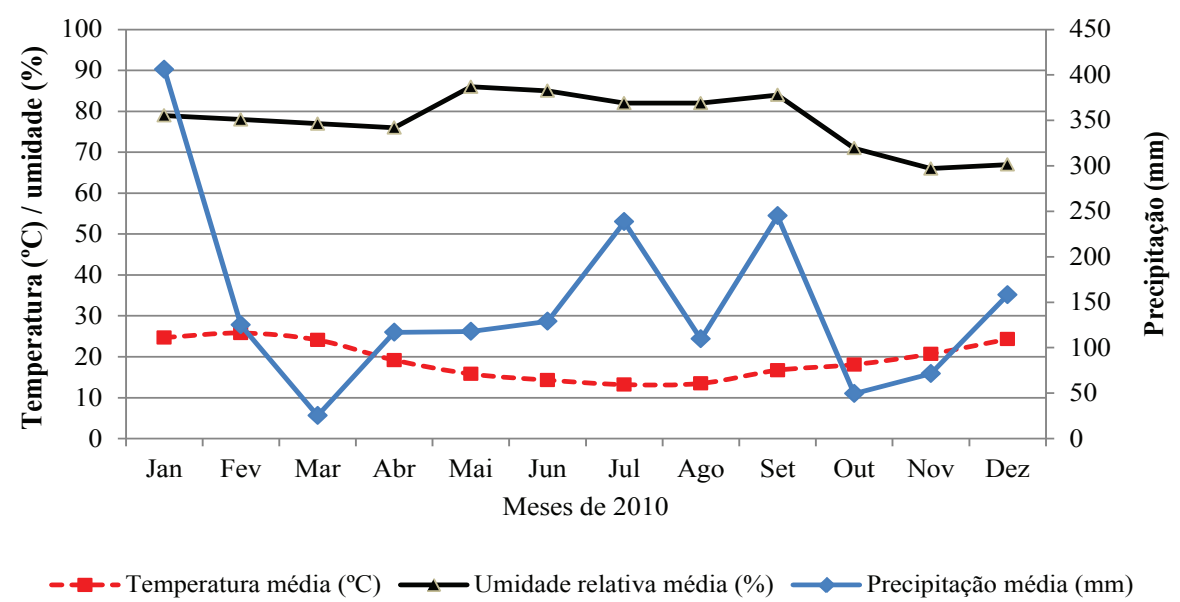

Figura 2. Condições climáticas do período de realização do ensaio, ano 2010. (Fonte: Estação Meteorológica da UFSM) 
de lixiviação, no qual há uma retirada parcial dos componentes do solo, os quais interferem na atividade fúngica. Seguindo a mesma linha, Silva et al. (2010) também encontraram uma diminuição da atividade fúngica nos períodos de maior precipitação, porém, observaram um aumento da população bacteriana no mesmo período chuvoso.

\section{Perda de massa}

A perda de massa (PM) observada na madeira tratada e não tratada de Eucalyptus grandis, submetidas ao campo de apodrecimento em duas situações distintas, campo aberto e floresta, pode ser observada na Tabela 2. De acordo com esses valores, observa-se que a madeira sem tratamento obteve a maior PM, quando comparada à madeira submetida ao tratamento preservativo. A PM pode ser considerada mínima, pois os valores não ultrapassaram $5 \%$, tanto para a madeira tratada quanto não tratada, no decorrer das avaliações realizadas.

Tabela 2. Perda de massa (\%) das estacas de Eucalyptus grandis submetidas ao campo de apodrecimento: campo aberto e floresta.

\begin{tabular}{|c|c|c|c|c|c|}
\hline \multicolumn{2}{|c|}{ Avaliação } & \multicolumn{2}{|c|}{ Não tratada } & \multicolumn{2}{|c|}{ Tratada } \\
\hline $\mathbf{N}^{0}$ & Dias & Campo & Floresta & Campo & Floresta \\
\hline 1 & 0 & \multicolumn{2}{|c|}{0,00} & \multicolumn{2}{|c|}{0,00} \\
\hline 2 & 60 & 0,76 & 1,04 & 0,74 & 0,96 \\
\hline 3 & 120 & 1,02 & 1,71 & 0,98 & 1,64 \\
\hline 4 & 180 & 2,12 & 2,23 & 2,00 & 2,06 \\
\hline 5 & 240 & 3,21 & 3,11 & 3,05 & 2,19 \\
\hline 6 & 300 & 4,22 & 4,59 & 4,10 & 4,07 \\
\hline
\end{tabular}

Foi observada nas amostras instaladas na floresta uma tendência de maiores perdas de massa em relação às amostras a campo aberto, o que corrobora com o encontrado por Trevisan (2006) e Melo et al. (2010). Com base na classificação utilizada para os ensaios de apodrecimento acelerado conduzidos em laboratório (American Society for Testing and Materials, 2005), a madeira das duas espécies em estudo podem ser enquadradas como altamente resistentes à deterioração, pois a perda de massa foi inferior a $10 \%$ durante o período de exposição a campo.

$\mathrm{Na}$ Tabela 3 encontra-se a PM da madeira de Eucalyptus cloeziana, tratada e não tratada, submetida ao campo de apodrecimento em duas situações distintas, campo aberto e floresta. A madeira de Eucalyptus cloeziana seguiu a mesma tendência da madeira de $E$. grandis, em que as amostras sem tratamento obtiveram maiores perdas de massa, quando comparadas às submetidas ao tratamento preservativo. Foi observado também nas peças instaladas na floresta maiores perdas de massa em relação às amostras a campo aberto.

Tabela 3. Perda de massa (\%) das estacas de Eucalyptus cloeziana submetidas ao campo de apodrecimento: campo aberto e floresta

\begin{tabular}{|c|c|c|c|c|c|}
\hline \multicolumn{2}{|c|}{ Avaliação } & \multicolumn{2}{|c|}{ Não tratada } & \multicolumn{2}{|c|}{ Tratada } \\
\hline $\mathbf{N}^{\mathbf{o}}$ & Dias & Campo & Floresta & Campo & Floresta \\
\hline 1 & 0 & \multicolumn{2}{|c|}{0,00} & \multicolumn{2}{|c|}{0,00} \\
\hline 2 & 60 & 1,00 & 1,25 & 1,15 & 1,54 \\
\hline 3 & 120 & 1,43 & 1,48 & 1,39 & 1,55 \\
\hline 4 & 180 & 1,74 & 2,21 & 1,99 & 1,66 \\
\hline 5 & 240 & 2,84 & 3,05 & 2,80 & 2,41 \\
\hline 6 & 300 & 4,13 & 4,17 & 3,75 & 3,96 \\
\hline
\end{tabular}

De acordo com American Society for Testing and Materials (2005), a madeira de Eucalyptus cloeziana pode ser classificada como altamente resistente à deterioração, pois a perda de massa foi inferior a $10 \%$ durante o período analisado.

Em relação às maiores perdas no ambiente florestal, Melo et al. (2010) justificaram que tal fenômeno ocorre em razão da alta umidade existente no ambiente da floresta, do armazenamento de água no solo (permanece úmido por vários dias após às chuvas) e da pouca infiltração de raios solares pelas copas, o que proporciona baixa luminosidade e temperaturas inferiores às alcançadas no ambiente de campo.

Já Trevisan (2006) afirmou que variações ambientais, principalmente com relação à temperatura e umidade, têm importância fundamental no desenvolvimento dos micro-organismos aptos ao ataque, e na velocidade de decomposição da madeira. Em contrapartida, uma maior exposição solar no ambiente de campo ocasiona processos mais bruscos de secagem e umedecimento, $o$ que proporciona o surgimento de tensões de secagem que podem provocar rachaduras na madeira. As aberturas produzidas pelas rachaduras podem acumular umidade, criando, deste modo, uma região de maior fragilidade ao ataque de fungos e, em sequência, às térmitas.

Nas Figuras 3 e 4 podem ser observadas as equações lineares ajustadas para estimativa da PM da madeira de Eucalyptus grandis e E. cloeziana, respectivamente, em função do número de dias em que as amostras permaneceram instaladas em campo de apodrecimento. 


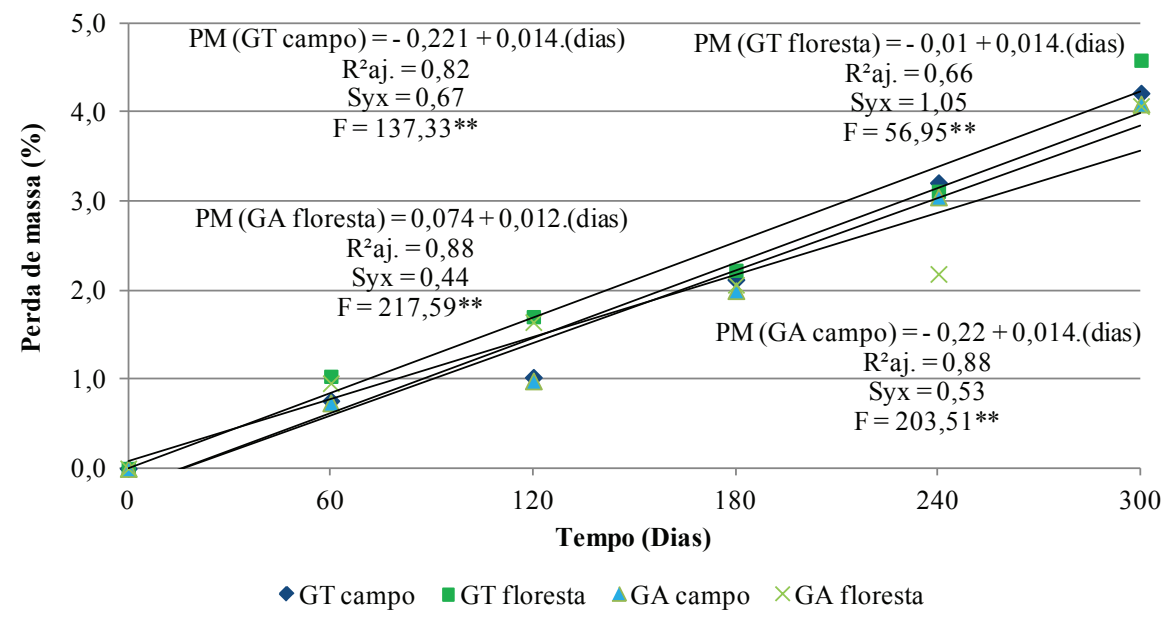

Figura 3. Perda de massa da madeira de Eucalyptus grandis em função do tempo em que as amostras permaneceram no campo de apodrecimento $\left(\mathrm{GT}=E\right.$. grandis não tratada; $\mathrm{GA}=$ E. grandis tratada). ${ }^{* *}$ significativo a $1 \%$ de probabilidade.

As informações (Figura 3) sugerem que todas as equações geradas para estimativa da PM em função do número de dias de exposição a campo para a madeira de Eucalyptus grandis possuem bons ajustes, com altos coeficientes de determinação e significativos a $1 \%$ de probabilidade de erro.

Para a madeira de Eucalyptus cloeziana (Figura 4) os ajustes das equações foram ainda mais significativos, observando-se coeficientes de determinação e valores de
F superiores. Desta forma, as equações geradas podem ser utilizadas como método confiável para estimativa da PM a partir do número de dias de exposição a campo.

Em ensaio de campo conduzido com madeira de açoita-cavalo, nogueira e plátano, Melo et al. (2010) também encontraram bons ajustes para as equações geradas para estimativa da PM em função dos dias de exposição a campo, com valores de coeficiente de determinação que variaram entre 0,40 e 0,84 .

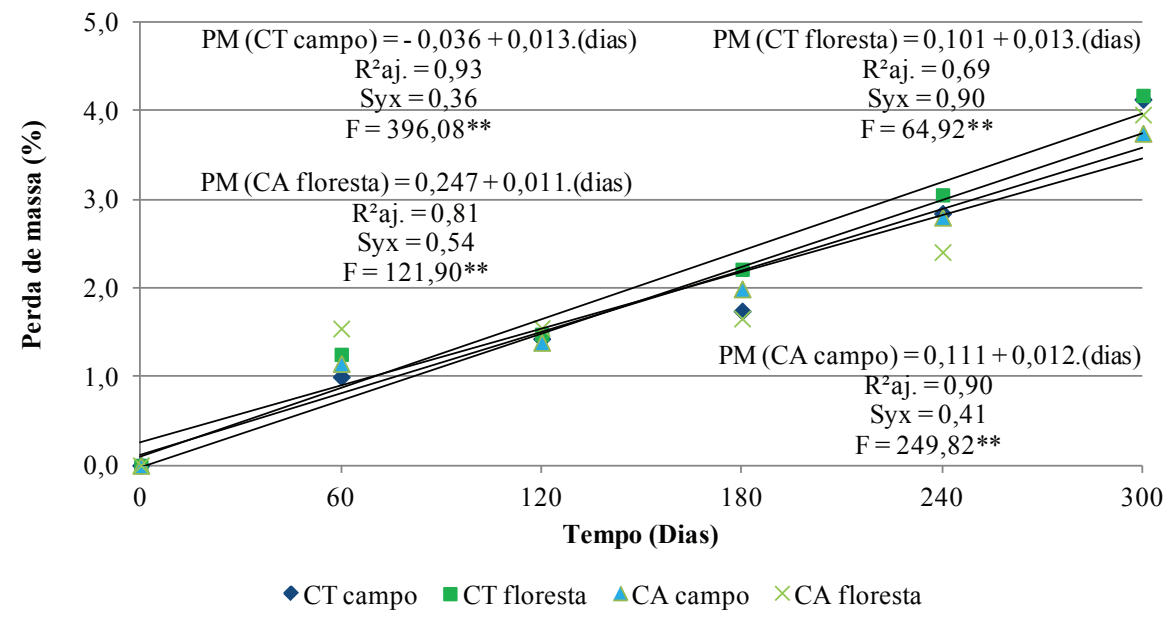

Figura 4. Perda de massa da madeira de Eucalyptus cloeziana em função do tempo em que as amostras permaneceram no campo de apodrecimento $\left(\mathrm{CT}=\right.$ E. cloeziana não tratada; $\mathrm{CA}=$ E. cloeziana tratada). ${ }^{*}$ significativo a $1 \%$ de probabilidade. 


\section{Índice de comportamento}

O índice de comportamento (IC) da madeira de Eucalyptus grandis, tratada e não tratada, submetida ao campo de apodrecimento em duas situações distintas, campo aberto e floresta, pode ser observado na Tabela 4. Verifica-se que os índices de comportamento mais altos, que representam maior expectativa de durabilidade, correspondem às peças tratadas, que foram submetidas ao tratamento com CCA. Contudo, mesmo as amostras sem tratamento apresentam índices de comportamento considerados satisfatórios.

Tabela 4. Índice de comportamento das estacas de Eucalyptus grandis submetidas ao campo de apodrecimento: campo aberto e floresta.

\begin{tabular}{c|c|cc|cc}
\hline \multicolumn{2}{c|}{ Avaliação } & \multicolumn{2}{c|}{ Não tratada } & \multicolumn{2}{c}{ Tratada } \\
\hline $\mathbf{N}^{\mathbf{0}}$ & Dias & Campo & Floresta & Campo & Floresta \\
\hline 1 & 0 & \multicolumn{2}{|c|}{100} & \multicolumn{2}{c}{100} \\
\hline 2 & 60 & 100 & 88 & 98 & 86 \\
\hline 3 & 120 & 94 & 88 & 98 & 88 \\
\hline 4 & 180 & 82 & 82 & 86 & 90 \\
\hline 5 & 240 & 78 & 78 & 82 & 82 \\
\hdashline 6 & 300 & 74 & 68 & 78 & 78 \\
\hline
\end{tabular}

Como pode ser observado na Tabela 4, o IC foi reduzindo-se com o decorrer do tempo de exposição ao ambiente. Entretanto, em relação à média, tanto os tratamentos quanto os ambientes não possuem deterioração intensa no final da avaliação, sendo esta considerada apenas moderada (próximo a 70).

Paes et al. (2002), em estudo realizado com a madeira de Eucalyptus grandis submetida ao tratamento com creosoto vegetal, após 12 meses a campo, observaram IC de 90 a 100 para madeira tratada, já no caso da madeira sem tratamento, o índice após este período foi de 40 a 70. No mesmo estudo, os autores observaram que a madeira submetida ao tratamento preservativo ainda apresentava um IC de 40 a 70 depois de 4 anos, enquanto que a madeira controle apresentava comportamento 0 , ou seja, perda total de resistência, o que validou o tratamento da madeira realizado pelos autores.

Por meio da Tabela 5, pode ser observado o IC da madeira de Eucalyptus cloeziana, tratada e não tratada, submetida ao campo de apodrecimento em duas situações distintas, campo aberto e floresta. Pode verificar-se que os valores encontrados para a espécie foram superiores aos do E. grandis, indicando que a madeira de E. cloeziana apresentam maior resistência quando exposta às condições adversas ou em contato com o solo.
Tabela 5. Índice de comportamento das estacas de Eucalyptus cloeziana submetidas ao campo de apodrecimento: campo aberto e floresta.

\begin{tabular}{c|c|cc|cc}
\hline \multicolumn{2}{c|}{ Avaliação } & \multicolumn{2}{c|}{ Não tratada } & \multicolumn{2}{c}{ Tratada } \\
\hline $\mathbf{N}^{\mathbf{0}}$ & Dias & Campo & Floresta & Campo & Floresta \\
\hline 1 & 0 & \multicolumn{2}{|c|}{100} & \multicolumn{2}{c}{100} \\
\hline 2 & 60 & 100 & 96 & 98 & 98 \\
\hdashline 3 & 120 & 96 & 98 & 98 & 98 \\
\hline 4 & 180 & 90 & 90 & 92 & 92 \\
\hline 5 & 240 & 86 & 86 & 86 & 90 \\
\hline 6 & 300 & 82 & 78 & 82 & 82 \\
\hline
\end{tabular}

As estacas de E. cloeziana possuem IC elevado, superiores a 90, até a quarta avaliação (180 dias) para ambos os tratamentos. Apenas a partir da quinta avaliação (240 dias), as peças demonstraram comportamento intermediário com ataque leve a moderado.

Os corpos de prova instalados dentro da floresta foram mais degradados em comparação com os de campo aberto nas duas espécies em estudo. Esse fato é compreensível em função das características ecológicas inerentes ao ambiente florestal, que favorecem a diversidade e a atuação dos organismos decompositores da madeira.

Trevisan et al. (2008), estudando o comportamento da madeira de cinco espécies florestais em função da deterioração em dois ambientes (campo aberto e floresta), também encontraram a mesma tendência, com maiores perdas na floresta em comparação com o campo aberto. Segundo os mesmos autores, após 12 meses de exposição ao ambiente, as madeiras de Eucalyptus urophylla e Inga marginata observaram, respectivamente, IC de 70 e 92 no campo aberto e 60 e 87 no ambiente florestal, comprovando a tendência encontrada no presente estudo.

Segundo Melo et al. (2010), a análise subjetiva atribuída por notas é o principal parâmetro para avaliação da durabilidade de madeiras em ensaios de campo de apodrecimento. Este procedimento é empregado em ensaios realizados com amostras de grandes dimensões, em que são realizadas avaliações visuais periodicamente, com posterior reintrodução no ambiente de teste. No entanto, Lopez \& Milano (1986) citaram que diversos pesquisadores utilizam, além das avaliações visuais como o índice de deterioração, um segundo parâmetro, que pode ser ensaio mecânico ou perda de massa, para melhor caracterizar a durabilidade natural de uma madeira em ensaios de campo. 
Outro fato observado foi a alteração de cor dos corpos de prova, principalmente nos que foram instalados em campo aberto, que apresentaram aspecto envelhecido. No entanto, as peças retiradas do interior da floresta apresentavam aspecto normal. Trevisan (2006) também constatou a mesma tendência, com a maioria dos corpos de prova procedentes do campo aberto apresentando coloração mais escura, quando comparados com os não atacados e com os procedentes do campo de apodrecimento instalado dentro da mata. $\mathrm{O}$ mesmo autor justificou que isto provavelmente é explicado pela atuação da degradação fotoquímica, pois a intensidade solar neste ambiente é superior com incidência da radiação ultravioleta direta, pela ausência de árvores, comparado ao ambiente de dentro da mata. Segundo Oliveira et al. (1986), a degradação fotoquímica é promovida pela radiação ultravioleta, que atua, principalmente, sobre a lignina, ocasionando como efeito perceptível a alteração da cor da madeira.
Nas Figuras 5 e 6 podem ser observadas as equações lineares ajustadas para estimativa do IC da madeira de Eucalyptus grandis e E. cloeziana, respectivamente, em função do número de dias em que as amostras permaneceram instaladas em campo de apodrecimento.

Como pode ser observado na Figura 5, todas as equações geradas para estimativa do IC em função do número de dias de exposição a campo para a madeira de Eucalyptus grandis possuem bons ajustes, com coeficientes de determinação aceitáveis, e F calculado significativo a $1 \%$ de probabilidade de erro. Já para madeira de Eucalyptus cloeziana (Figura 6), os ajustes encontrados foram ainda mais significativos do que para a madeira $E$. grandis, sendo observados coeficientes de determinação superiores e maiores valores de $\mathrm{F}$, o que indica que as equações obtidas pelo modelo podem ser utilizadas como método confiável para estimativa do IC com base no tempo de exposição a campo.

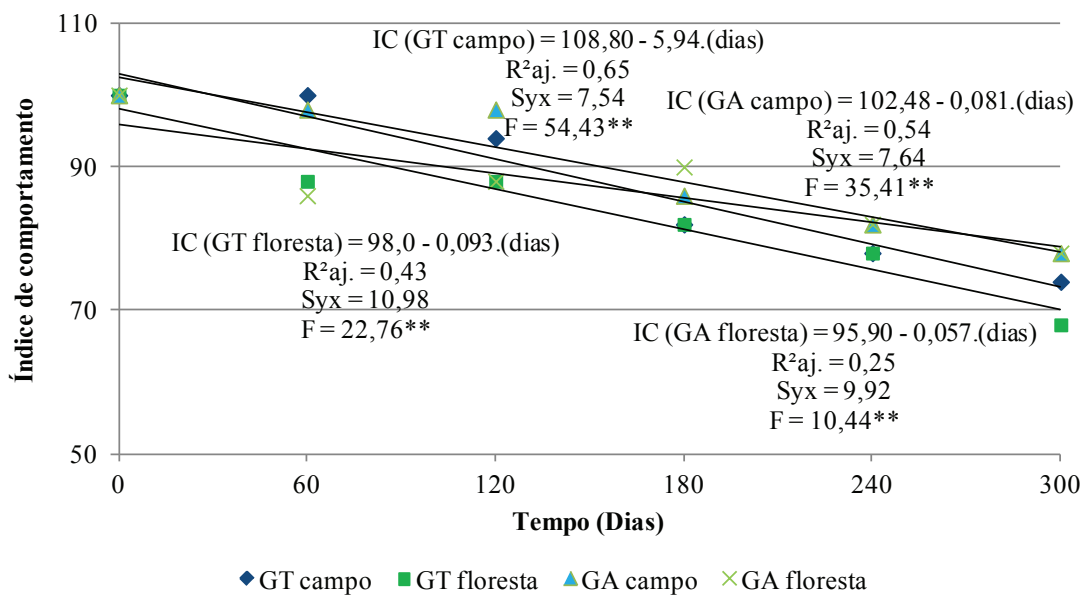

Figura 5. Índice de comportamento da madeira de Eucalyptus grandis em função do tempo em que as amostras permaneceram no campo de apodrecimento $\left(\mathrm{GT}=\right.$ E. grandis não tratada; $\mathrm{GA}=$ E. grandis tratada). ${ }^{* *}$ significativo a $1 \%$ de probabilidade.

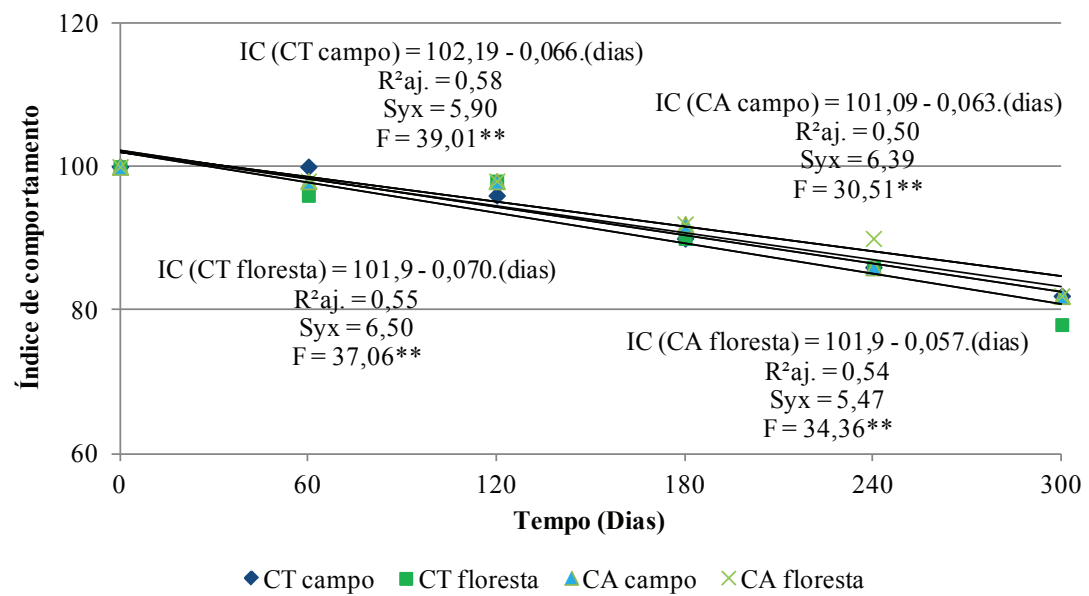

Figura 6. Índice de comportamento da madeira de Eucalyptus cloeziana em função do tempo em que as amostras permaneceram no campo de apodrecimento $\left(\mathrm{CT}=\right.$ E. cloeziana não tratada; $\mathrm{CA}=$ E. cloeziana tratada). ${ }^{* *}$ significativo a $1 \%$ de probabilidade. 


\section{Conclusões}

Houve perda de massa das peças expostas ao campo de apodrecimento, tanto no ambiente florestal quanto no campo aberto;

O tratamento com CCA proporciona índice de comportamento superior às peças tratadas no caso das duas espécies em estudo, com valores satisfatórios ao longo do tempo de exposição a campo.

\section{Referências}

AMERICAN SOCIETY FOR TESTING AND MATERIALS. ASTM D 2017: Standard test method for accelerated laboratory test of natural decay resistance of wood. Philadelphia, 2005. 5 p.

BARILLARI, T. C. Durabilidade da madeira do gênero Pinus tratada com preservantes: avaliação em campo de apodrecimento. 200268 f. Dissertação (Mestrado em Ciências Florestais) - Escola Superior de Agricultura Luiz de Queiroz, Piracicaba, 2002.

BARILLARI, T. C.; FREITAS, V. P. Preservação. Revista da Madeira, São Paulo, n. 68, dez. 2002..

CALIL JÚNIOR, C.; DIAS, A. A. Utilização da madeira em construções rurais. Revista Brasileira de Engenharia Agrícola e Ambiental, Campina Grande, v. 1, p. 71-77, 1997.

GOLFARI, L.; CASER, R. L.; MOURA, V. P. G. Zoneamento ecológico esquemático para o reflorestamento no Brasil. Brasília, DF, Ministério da Agricultura, 1978. (PRODEPEF. Série técnica, 11).

LEPAGE, E. S. Método padrão sugerido pela IUFRO para ensaios de campo com estacas de madeira. Preservação de Madeiras, São Paulo, v. 1, n. 4, p. 205-216, 1970.

LOPEZ, G. A. C.; MILANO, S. Avaliação da durabilidade natural da madeira e de produtos usados na sua proteção. In: LEPAGE, E. S. (Coord.). Manual de preservação de madeiras. São Paulo: IPT; SICCT, 1986. v. 2. p. 473-510.

MELO, R. R.; STANGERLIN, D. M.; SANTINI, E. J.; HASELEIN, C. R.; GATTO, D. A.; SUSIN, F. Durabilidade da madeira de três espécies florestais em ensaios de campo. Ciência Florestal, v. 20, n. 2, p. 357-365, 2010.
MENDES, A. S.; ALVES, M. V. S. A degradação da madeira e sua preservação. Brasília, DF: IBDF/DPq-LPF, 1988. 58 p.

MONTEIRO, A. C. Influência da sazonalidade, dos teores de matéria orgânica, $\mathrm{pH}$ e umidade na ocorrência de fungos entomopatogenicoos no solo. In: SIMPÓSIO BRASILEIRO DE MICROBIOLOGIA DO SOLO, 3.,1994. Resumos. Londrina: IAPAR, 1994.

OLIVEIRA, A. M. F.; LELIS, A. T.; LEPAGE, E. S.; CARBALLERA LOPEZ, G. A.; OLIVEIRA, L. C. S.; CAÑEDO, M. D.; MILANO, S. Agentes destruidores da madeira. In: LEPAGE, E. S. (Coord.) Manual de preservação de madeiras. São Paulo: IPT, 1986. p. 99-279.

PAES, J. B.; VITAL, B. R.; DELLA LUCIA, R. M.; DELLA LUCIA, T. R. C. Efeitos da purificação e do enriquecimento do creosoto vegetal na preservação da madeira de Eucalyptus grandis, após 48 meses de instalação do ensaio de campo. Revista Árvore, Viçosa, MG, v. 26, n. 4, p. 475-484, 2002.

SALES-CAMPOS, C.; VIANEZ, B, F.; MENDONÇA, M. S. Estudo da variabilidade da retenção do preservante CCA tipo A na madeira de Brosimum rubescens Taub. Moraceae - (pau-rainha) uma espécie madeireira da região Amazônica. Revista Árvore, Viçosa, MG, v. 27 , n. 6 , p. $845-853,2003$.

SILVA, R. B.; MOURA Q.; RODRIGUES H.; BARRETO, P.; NUNES, H.; RODRIGUES, R.; SANTOS, S.; RUIVO, M. L. Estudo das colônias de fungos e bactérias em solos de floresta tropical associada à variação das chuvas na região. In: CONGRESSO BRASILEIRO DE METEOROLOGIA, 26., 2010, Belém. Anais eletrônicos... Belém, 2010. Disponível em: <http://www.cbmet2010. com/anais/4.html>. Acesso em: 24 jan. 2011.

TREVISAN, H. Degradação natural de toras e sua influência nas propriedades físicas e mecânicas da madeira de cinco espécies florestais. 2006. 69 f. Dissertação (Mestrado em Ciências Florestais) - Universidade Federal Rural do Rio de Janeiro, Seropédica.

TREVISAN, H.; MARQUES, F. M. T.; CARVAlHO, A. G. Degradação natural de toras de cinco espécies florestais em dois ambientes. Floresta, PR, v. 38, n. 1, jan./mar. p. 33-41, 2008. 
